\title{
Early predictors of career development: A 10-year follow-up study
}

\author{
Joaquim Armando Ferreira a,*, Eduardo J.R. Santos a, \\ António C. Fonseca ${ }^{\mathrm{a}}$, Richard F. Haase ${ }^{\mathrm{b}}$ \\ a Faculdade de Psicologia e de Ciências da Educação, Universidade de Coimbra, Rua do Colégio Novo, \\ P-3000 Coimbra, Portugal \\ ${ }^{\mathrm{b}}$ University at Albany, State University of New York, USA
}

Received 23 March 2006

Available online 9 June 2006

\begin{abstract}
This paper presents empirical findings from a 10-year longitudinal study of the educational and occupational socialization of 445 participants who were about 7 years old when first tested, and about 17 years old at the fourth time of measurement. In addition to collecting psychological measurements from the participants, behavioral reports were collected from significant others, specifically parents and teachers. Findings demonstrated that the life/career evolution of the participants can be understood only when taking into account the dynamic interaction between the unique personal characteristics of individuality of each person and the psychosocial theatre within which the person's development takes place. Using the life-span, life-space framework of Super, and the Developmental-Contextual model from Vondracek, different emerging early predictors with unique impact on the process of educational and occupational socialization were identified, especially with respect to the probability of dropping out of school. Results in terms of gender, parental influences, psychological characteristics, and social context are discussed with regard to their potential implications for psychological interventions in schools, families, and occupational settings, as well as with regard to personal counseling in what concerns the management of life circumstances and behavioral ecosystems.
\end{abstract}

(c) 2006 Elsevier Inc. All rights reserved.

\footnotetext{
This study was funded by the Portuguese Science and Technology Foundation, Grant No. POCTI/36532/PSI $/ 2000$.

* Corresponding author.

E-mail address: jferreira@fpce.uc.pt (J.A. Ferreira).
} 
Keywords: School dropout; Developmental-Contextual variables; Career development; Career education and guidance

\section{Introduction}

The pioneering work of Super and collaborators (cf. Super, Savickas, \& Super, 1996) on his developmental conception of careers led to the recognition that longitudinal studies represent one of the major methodological means to enhance our understanding of vocational behavior and related topics. Using a predictor-criterion methodology, he demonstrated that it is possible to forecast vocational behaviors and to influence them; this was one of the most significant outcomes of the career pattern study (CPS) (cf. Super, 1957, 1990).

Super's life-span, life-space conceptual framework (Super, 1980) is one of the most powerful foundations of narrative approaches in the study of careers, so well represented by the work of Savickas $(2002,2005)$, and also of the action perspectives represented by the research of Young, Valach, and Collin (1996). Super, as well as Pepper (1942), served as a part of the foundation of the paradigmatic work of Vondracek and his well known Developmental-Contextual model (Vondracek \& Porfeli, 2002; Vondracek, Lerner, \& Schulenberg, 1986). Merging the three above-mentioned perspectives could yield a systemic-ecological model explaining the career process of selecting vocational options and adjusting later within the world of work, a discussion that has already been initiated by others (e.g., Patton \& McMahon, 1998).

Development always takes place in a social context, which Super called the life-space. Within this space, individuals develop and try to implement their vocational self-concepts (Super, 1963, 1981; Super et al., 1996). This self-concept and other relevant vocational processes and behaviors are learned in a variety of ways, including vicariously by observing behaviors modeled by parents and other significant role models (cf. Bandura, 1986; Lent, Brown, \& Hackett, 1996). Ultimately, career choices are made within the context of several social networks (family, peers, school, community, etc.). This process is constructionist in nature, following several steps, or stages, that have been well described by both Super (1980) and Crites (1969). The life-space has a concomitant life-span reality that should be one of our main concerns in vocational research; this means that longitudinal studies are recommended (cf. Reitzle \& Vondracek, 2000).

Vocational personality expresses itself within life-span themes, as efforts are made to adapt to the world of work and its rules. Along this longitudinal process of adaptation to the world of work, several developmental tasks must be performed, as a necessary condition for progressing as a person, a worker, and a citizen. There are questions to be answered, problems to be solved, attitudes and beliefs to be expressed, and competences to be gained. Moreover, behaviors must be constructed to cope with life demands, with relationships, and finally, for desirable career outcomes to occur, a full behavioral system capable of dealing effectively with the world of work must be acquired. That is the challenge for the future (Savickas, 2003a, 2003b).

Career construction and life themes are anchored in person-environment fit dimensions, including cultural and social contexts. Vocational behaviors represent contextualized actions that arise out of the joint consideration of individual, family, school, peer, and 
community "desires," which become organized as careers. The way that society and the individual understand this course of action, and give it meaning, will make a difference in the experienced emotions of the real situations lived through the life course, and in the social validity of the overall vocational behaviors (Collin \& Young, 2000).

Vondracek's work challenges us to work toward understanding how three systems interface within vocational development: the personal, the contextual, and the dyadic personal-contextual interaction. Using Vondracek's Developmental-Contextual model (Vondracek et al., 1986), as well as the more recently advanced Developmental Systems Theory of Ford and Lerner (1992) as theoretical contexts, it may be possible to gain a better understanding of the complex roles of awareness and the impact of the multiple developmental contexts on children and adolescents' vocational behavior (Hartung, Porfeli, \& Vondracek, 2005; Vondracek, 2001; Wiesner, Vondracek, Capaldi, \& Porfeli, 2003). Transitions must also be understood not only as outcomes of the developmental stages, but, essentially, as a new object of research (Reitzle, Vondracek, \& Silbereisen, 1998; Vondracek \& Porfeli, 2004). Moreover, they must be viewed as being shaped by individual characteristics and multiple levels of context, as well as chronological factors.

The types of studies that are promoted by these perspectives have to do with how intra-individual and contextual factors affect school behaviors and out-of-school behaviors, how exposure to differing contexts affects career development, how self-efficacy emerges throughout this process and how hopefulness arises. Other inquiries that could be envisioned from these perspectives include investigations of how self-perceptions related to vocational development may be misconstrued, how exploratory behavior may be stifled, and how self-concepts may be biased through misleading identity patterns. In short, a dynamic, non-recursive, systemic perspective challenges us to abandon a strictly linear and variable-based way of thinking and empowers us to address intriguing questions that deal with the emerging post-modern world (Vondracek, Reitzle, \& Silbereisen, 1999).

Given this theoretical background, the aim of the present study was to explore the predictive power of some early personal and social indicators of selected school and occupational dimensions on the likelihood of remaining in school during the adolescent period. We present in this study some data that addresses the forecast of "still being in school" in late adolescence, or "being out of school (working or not)" - early occupational socialization. We selected for study several psychological dimensions of behavior, given their face validity related to the purpose of the study, as well as contextual factors existing during the process of school socialization, and their interactions.

We know now that career choice and development are matters not exclusively associated with adolescence or adulthood; childhood and its contexts are also important precursors of future vocational behaviors. We need to analyze what happens with children in interaction with their environments, in a Developmental-Contextual theoretical and methodological framework, in order to predict behaviors like school dropout, which are so dramatically important in vocational terms. Leaving school prematurely and entering the world of work may at least prompt circumscription (Gottfredson, 1996) if not foreclosure (Marcia, 1976). What could predict a normal process of school socialization, and related vocational outcomes? What could predict school dropout and early occupational socialization, and related outcomes?

As Herr and Cramer (1996) state, the process of personal and educational learning that occurs within elementary school children, and in interaction with their family and social 
contexts, has crucial importance for their vocational and career development. So, if school dropout occurs during child or adolescent development, then this statement acquires an even more dramatic meaning. To dropout of school early is to be removed from a normative process of personal and vocational development, and therefore to suffer arrested development in an important career and occupational process, with all the psychosocial implications that may follow. Performing school tasks can be envisioned as prototypes of performing future work tasks; as these authors suggest - "the fundamental point is that what happens in the life of the child in the elementary school does create patterns of behavior, positive or negative, that are likely to persist into the secondary school and adulthood" (op. cit., p. 352). If so, we wonder what would happen if individuals dropout of school and fail to develop the patterns of behavior that may persist into later years.

This study specifically examines the developmental period (i.e., life-space) spanning middle childhood (from 7 years old) through later adolescence (up to 17 years old). The aim of this study is to employ the predictor-criterion approach to assess the factors from early elementary school that might predict the processes of school and occupational socialization. We were especially interested in the factors that might predict when adolescents make a premature transition from school to work.

\section{Methods}

\subsection{Participants}

Four-hundred and forty-five participants were assessed at four different times across a 10 year interval; participants were drawn from an ongoing longitudinal study on learning, socialization, and problem behaviors, at the University of Coimbra, Portugal (Fonseca, Simões, Rebelo, \& Ferreira, 1995; Fonseca, Rebelo, \& Damião, 2005; Simões, Ferreira, Fonseca, \& Rebelo, 1995). The original sample consisted of 1586 children and adolescents who in 1992-1993 attended 2nd, 4th, and 6th grades in state schools, randomly selected from urban, suburban, and rural areas of the municipality of Coimbra (central Portugal). The data presented in this paper are based on 445 children (girls and boys) who were assessed for the first time in 1993 when they attended the 2 nd grade, and the participants' average age was 7 . The second period of assessment was in 1997 when participants were 11 years of age, and the third was in 2000, when the participants were, on average, 14 years of age. Finally, the fourth period of evaluation was conducted in 2003, when participants were between 17 and 18 . At the fourth period 297 students were still in school (136 males and 161 females) and 143 students had already dropped out of school and had made an early transition to work (101 males and 42 females). Out of the 143 participants who had dropped out of school only one indicated that they ever had a job, and five did not respond to that item. Thus, the vast majority was working in low skill and low paid jobs or had for periods of time different jobs or temporary work.

The expectations to enter college (assessed at time 3, when they should be attending 9th grade) were quite different for both groups. For participants who remained in school, $84.3 \%$ expressed a desire to pursue their studies and attend college, while only $26 \%$ of the participants who dropped out and entered the world of work (prematurely) expressed a desire to enter college. Of the group who dropped out of school, 23.4\% indicated a desire to enter some sort of vocational training course (compared to $.5 \%$ of the group that 
remained in school); $16.9 \%$ (compared to $3.6 \%$ of the group that remained in school) wanted to only finish compulsory school (9th grade in Portugal), and $14.3 \%$ manifested an intention to start working right away (compared to $2.6 \%$ of the group that remained in school).

The reasons for dropping out of school were diverse but can be summarized as follows: Found a job that they liked (15.4\%); hated school (15.4\%); had bad grades and school retentions (12.1\%); had economic problems (10.1\%); found that studies did not match aspirations $(8.7 \%)$; experienced family problems $(2.7 \%)$; realized that studies were not a guarantee to find a job $(2 \%)$.

\subsection{Instruments}

Several psychological, behavioral, and contextual measures were administered over the 10 year period covered by a large-scale developmental study. From these we selected measures that were focused on capturing the developmental antecedents of several psychosocial behaviors (delinquency, mental health problems, socialization processes, etc.) thought to be relevant for understanding career development.

At time 1 of this study (1992-1993), parents completed the child behavior checklist (CBCL; Achenbach, 1991a). Teachers completed the teacher report form (TRF; Achenbach, 1991b) and students filled in a Portuguese adaptation of the self-report questionnaire of antisocial behavior (SRA; Loeber, Stouthamer-Loeber, Van Kamen, \& Farrington, 1989). The CBCL and the TRF yielded scores for antisocial behavior and emotional problems, plus eight empirically derived syndromes, including separate scales of aggression, delinquency, and attention problems. The SRA provides a global score of antisocial behavior and some separately scored scales (e.g., theft, vandalism). For the purpose of the present study, we used only global scores on the above-mentioned instruments. At times 2, 3, and 4, participants were assessed regarding their status within the school system (including reasons in case of dropout, and expectations towards the future).

\subsection{Procedure}

The participants were part of an ongoing longitudinal study on learning, socialization and problem behaviors, who were first tested in 1993 and then were followed up and tested three more times in 1997, 2000, and 2003. The data were collected by trained researchers working for the project, in individual or group sessions in schools, following the necessary authorization granted by parents and school principals, and at participants' homes, for those participant who had droped out of school.

\section{Results}

\subsection{Analytic plan}

The primary focus of this project was on the individual, family, and contextual factors that would predict the likelihood of a student to dropping out of school and making the transition to work prior to completion of the school curriculum at grade 12. Among the several methods available for the analysis of longitudinal data, the methods of survival analysis (Cox \& Oakes, 1984; Lee, 1992; Selvin, 1991; Singer \& Willett, 1991) and propor- 
tional hazards regression analysis (Cox, 1972) are especially suited to modeling the probability of an event, such as dropping out of school, especially when the event can occur across time. In these analyses the survivor function, $S(t)$, is an estimate of the probability that a randomly chosen student will "survive" to time $t+1$, provided that the student had not experienced the event (dropout) at time $t$. Conversely, the hazard function documents the estimated probability that a randomly chosen student will experience the event (dropout) at time $t+1$, conditioned on the fact that the student had not experienced the event at time $t$. Survival and proportional hazard models can be fitted to continuous or discrete data, depending on the level of measurement of the time period. The time period in this study was measured discretely at grades 2 through 12 and a dropout event could occur at any of the 10 discrete grades. The survivor function is frequently used to provide the descriptive aspects of the changing probabilities across time, and the hazard function is more frequently used for the modeling process of testing differences in the hazard distribution as a function of one or more predictor variables in a regression model.

\subsection{Survivor and hazard functions}

Among the 445 students enrolled in this study in 1993, 440 students had data sufficient to be included in this analysis following the last measurement period in 2003. Among the 440 students who began the study in 1993, 143 students left school over the course of the next 10 years. The grade at which each of these students left school was documented. Additionally, 297 students in the sample did not dropout and remained in school through grade 12. The survivor function of the 440 students of this study, estimated by the KaplanMeier product limit method (Lee, 1992) is shown in Table 1.

The survivor function can be plotted to reveal a visual representation of the probability of surviving across time. Survivor functions for discrete time periods are step functions, while the survivor function presented in Fig. 1 is a spline smoothed survivor function (Lee, 1992; Miller, 1981). The smoothing process yields an approximation to a continuously distributed time variable and is usually visually more appealing than the step function. Examination of Fig. 1 suggests that the probability of surviving into each time (grade) period is a decreasing function of time with about $90 \%$ of students

Table 1

Survival table of school dropouts of 440 students for the years 1993-2003

\begin{tabular}{rlcl}
\hline Grade & $\begin{array}{l}\text { Cumulative proportion } \\
\text { surviving at the grade }\end{array}$ & $\begin{array}{l}\text { Number of cumulative } \\
\text { events }\end{array}$ & $\begin{array}{l}\text { Number of remaining } \\
\text { cases }\end{array}$ \\
\hline 2 & 1.000 & 0 & 440 \\
3 & 1.000 & 0 & 440 \\
4 & .989 & 5 & 435 \\
5 & .968 & 14 & 426 \\
6 & .920 & 35 & 405 \\
7 & .877 & 54 & 386 \\
8 & .820 & 79 & 361 \\
9 & .693 & 139 & 305 \\
10 & .682 & 140 & 300 \\
11 & .677 & 142 & 298 \\
12 & .675 & 143 & 297 \\
\hline
\end{tabular}





Fig. 1. Hazard function of 440 students for the years 1993-2003.

surviving (staying in school) up to grade six. Between grades 6 and 9 there is a fairly precipitous drop in survival denoted by a steepening slope of the function. Approximately $68 \%$ of the students "survived" to grade 12 , and the estimated mean of the survivor function is a grade level of 10.6.

The converse of the survivor function is the hazard function in which the estimated probability of experiencing the event (dropout) is plotted against time. The hazard function for these data is also presented in Fig. 1. The probability of experiencing the event is clearly increasing across time. The probability of dropping out of school increases from $0 \%$ at grade 3 to about $10 \%$ by grade 6 . The hazard increases rather dramatically to about $37 \%$ by grade 9 and then does not rise appreciably thereafter. Clearly, the probability of dropping out of school is an increasing function of time. 


\subsection{Modeling the time to event}

The main advantage of assessing hazard functions such as that depicted in Fig. 1 is that the entire distribution can then be modeled as a function of one or more predictor variables. The regression models introduced by Cox (1972) provide for the solution of a model in which shifts in the hazard distribution function, $h(t \mid x)$, can be modeled as an exponential function of a set of $k$ regressors,

$$
h(t \mid x)=h_{0}(t) \mathrm{e}^{\beta_{1} x_{1}+\beta_{2} x_{2}+\cdots+\beta_{k} x_{k}} .
$$

The baseline hazard, $h_{0}(t)$, is assumed to be a constant, and the $k$ regressors of the model can be either continuous or categorical in form. The term $h(t \mid x)$ in the model is the predicted hazard and is the conditional probability of dropping out at time $t$, given that the student was in the risk set at time $t-1$, and further conditioned on the values of the predictor variables, $x_{1}, x_{2}, \ldots, x_{k}$. The technical details of estimating the parameters of the model by maximum likelihood methods are presented in Cox (1972), Cox and Oakes (1984), Lee (1992) and Selvin (1991).

The predictor variables that were measured in this study included several individual, family, and contextual/school variables, which can be roughly ordered in terms of their chronological appearance. The first set of temporally precedent variables that may predict the probability of school dropout included an individual variable of the gender of the student, mother's, and father's education, and mother's and father's socioeconomic status. A second set of variables that were measured after the child was in school included a parent's and a teacher's ratings of the child's characteristics and behaviors (CBCL and TRF), and a self-report measure of antisocial behavior by the child (Antisocial). Finally, a potentially predictive school characteristic variable - urban versus rural, was included in a final step of the analysis. The means, standard deviations, and correlations among these predictors are displayed in Table 2. Sample sizes for the single predictor models varied from a low of 344 (mother's education) to a high of 440 (urban-rural) and hence each model was fitted with a slightly different sample size. Given the strength of the findings and the clarity of the results the effects of the variations in sample size are negligible.

A hierarchical Cox proportional hazards regression model was fitted to the hazard function in four steps: (1) the student's gender was entered into the equation; (2) mother's and father's education was added to gender; (3) the parents' and teacher's ratings of the child's behavior and the child's own ratings of antisocial behavior were added to the variables of the previous two steps; (4) mother's and father's socioeconomic status was added to the variables of step 3; (5) the urban-rural school characteristic variable was added to the variables of the previous four steps. At each step of the hierarchical analysis an overall test of the significance of the increment of the variables added at that stage was performed by a likelihood ratio $\chi^{2}$ test, and the unique contribution of each variable, controlling for all other variables in the model at that step, was evaluated by a Wald $\chi^{2}$ test. In addition to the hierarchical models, individual single predictor models were fitted to the hazard function to assess the contribution of each of these variables to the probability of dropping out of school in the absence of confounding or multicollinearity with the remaining predictor variables. The results of both the hierarchical Cox regression models and the single predictor variable models are summarized in Table 3.

The single predictor models fitted individually to the hazard function revealed that each of the predictor variables was a statistically significant predictor of the probability of 
Table 2

Means, standard deviations, and correlations of the variables used in the Cox regression analyses

\begin{tabular}{|c|c|c|c|c|c|c|c|c|c|c|}
\hline Variable & Dropout & Gender & Father's education & Mother's education & Father's SES & Mother's SES & Antisocial & CBCL & TRF & Urban-Rural \\
\hline Dropout & 1.00 & & & & & & & & & \\
\hline Gender & -.23 & 1.00 & & & & & & & & \\
\hline Father's education & -.36 & .14 & 1.00 & & & & & & & \\
\hline Mother's education & -.42 & .07 & .79 & 1.00 & & & & & & \\
\hline Father's SES & .22 & -.02 & -.55 & -.48 & 1.00 & & & & & \\
\hline Mother's SES & .35 & -.01 & -.62 & -.72 & .51 & 1.00 & & & & \\
\hline Antisocial & .26 & -.20 & -.13 & -.17 & .08 & .12 & 1.00 & & & \\
\hline CBCL & .27 & -.14 & -.24 & -.29 & .13 & .20 & .16 & 1.00 & & \\
\hline TRF & .37 & -.15 & -.10 & -.19 & .04 & .08 & .17 & .36 & 1.00 & \\
\hline Urban-Rural & .09 & .00 & -.26 & -.24 & .24 & .22 & -.02 & .06 & .03 & 1.00 \\
\hline Mean & .33 & .46 & 6.74 & 6.49 & 2.90 & 3.37 & 2.77 & 35.95 & 23.51 & .40 \\
\hline$S D$ & .47 & .50 & 3.37 & 3.42 & .75 & .89 & 4.60 & 20.63 & 22.51 & .49 \\
\hline$N$ & 440 & 445 & 349 & 347 & 427 & 436 & 442 & 394 & 431 & 445 \\
\hline
\end{tabular}


Table 3

Hierarchical Cox proportional hazards model of school dropout

\begin{tabular}{|c|c|c|c|c|c|c|c|c|c|c|}
\hline \multirow[t]{2}{*}{ Variables } & \multicolumn{6}{|c|}{ Hierarchical model } & \multicolumn{4}{|c|}{ Single predictor models } \\
\hline & $\beta$ & $\chi^{2}$ & $p$ & $\mathrm{e}^{\beta}$ & $\Delta \chi^{2}$ & $p$ & $\beta$ & $\chi^{2}$ & $p$ & $\mathrm{e}^{\beta}$ \\
\hline \multicolumn{11}{|l|}{ Step 1} \\
\hline Gender & -.85 & 12.99 & $<.001$ & .43 & 14.33 & $<.001$ & & & & \\
\hline Step 2 & & & & & 66.00 & $<.001$ & & & & \\
\hline Gender & -.83 & 12.07 & $<.001$ & .44 & & & & & & \\
\hline Mother's education & -.34 & 19.05 & $<.001$ & .71 & & & & & & \\
\hline Father's education & -.06 & .96 & .326 & .95 & & & & & & \\
\hline Step 3 & & & & & 33.84 & $<.001$ & & & & \\
\hline Gender & -.57 & 5.56 & .018 & .56 & & & & & & \\
\hline Mother's education & -.27 & 13.37 & $<.001$ & .76 & & & & & & \\
\hline Father's education & -.09 & 2.58 & .109 & .91 & & & & & & \\
\hline Antisocial & .05 & 10.66 & .001 & 1.05 & & & & & & \\
\hline CBCL & .004 & .70 & .404 & 1.00 & & & & & & \\
\hline Teacher's rate & .02 & 17.30 & $<.001$ & 1.02 & & & & & & \\
\hline Step 4 & & & & & 4.33 & .115 & & & & \\
\hline Gender & -.60 & 5.96 & .015 & .55 & & & & & & \\
\hline Mother's education & -.23 & 8.75 & .003 & .79 & & & & & & \\
\hline Father's education & -.06 & 1.04 & .308 & .94 & & & & & & \\
\hline Antisocial & .05 & 9.68 & .002 & 1.05 & & & & & & \\
\hline CBCL & .003 & .38 & .537 & 1.00 & & & & & & \\
\hline Teacher's rate & .02 & 18.75 & $<.001$ & 1.02 & & & & & & \\
\hline Mother's SES & .40 & 3.18 & .074 & 1.49 & & & & & & \\
\hline Father's SES & .12 & .37 & .541 & 1.13 & & & & & & \\
\hline Step 5 & & & & & .07 & .796 & & & & \\
\hline Gender & -.59 & 5.90 & .015 & .55 & & & -.86 & 21.70 & $<.001$ & .43 \\
\hline Mother's education & -.23 & 8.76 & .003 & .79 & & & -.34 & 49.19 & $<.001$ & .72 \\
\hline Father's education & -.06 & .99 & .319 & .94 & & & -.24 & 38.82 & $<.001$ & .79 \\
\hline Antisocial & .05 & 9.55 & .002 & 1.05 & & & .06 & 31.42 & $<.001$ & 1.06 \\
\hline CBCL & .003 & .43 & .511 & 1.003 & & & .02 & 31.03 & $<.001$ & 1.02 \\
\hline Teacher's rate & .02 & 18.82 & $<.001$ & 1.02 & & & .03 & 78.46 & $<.001$ & 1.03 \\
\hline Mother's SES & .40 & 3.16 & .075 & 1.49 & & & .91 & 38.48 & $<.001$ & 2.48 \\
\hline Father's SES & .13 & .39 & .531 & 1.13 & & & .51 & 16.94 & $<.001$ & 1.66 \\
\hline Urban-Rural & -.06 & .07 & .796 & .944 & & & .27 & 2.67 & .102 & 1.32 \\
\hline
\end{tabular}

$\beta$ are the regression coefficients of the Cox regression model. $\chi^{2}$ is a Wald test of the statistical significance of the regression coefficient. $\Delta \chi^{2}$ is a test of the significance of the increment of a step over the previous step of the model. $\mathrm{e}^{\beta}$ is the odds ratio corresponding to a one unit change in the predictor variable.

dropping out of school, with the exception of the urban-rural school characteristic distinction. The probability of school dropout for the male students in the sample was significantly different (elevated) from the probability of school dropout for females across all grades. Males are significantly more likely to dropout over the course of the school years than are the females. The differences in dropout probabilities between males and females were relatively constant up to about grade 9 , at which point the probability of dropping out for males (.55) is even more discrepant from the hazard for females (.22) at this grade level. Similarly, mother's education and father's education were individually significant predictors of the probability of dropout. 
Fig. 2 presents the hazard functions for mother's education and father's education broken down into low, medium, and high groups for purposes of illustration. As both mother's or father's education increases, the probability of dropping out of school across the 10-year period decreases sharply-higher parental education is significantly associated with less school dropout in this sample. Similar patterns were observed for both mother's and father's socioeconomic status - as SES increases, the probability of dropping out of school decreases noticeably. A plot of the hazard function of mother's and father's SES is not presented here; the function shapes for low, medium, and high groups are quite similar to the function shapes presented in Fig. 2 for mother's and father's eduction.

Fig. 3 displays the hazard function of antisocial behavior as rated by the child. Antisocial behavior was trichotomized into low, medium, and high groups to facilitate the graphic presentation.
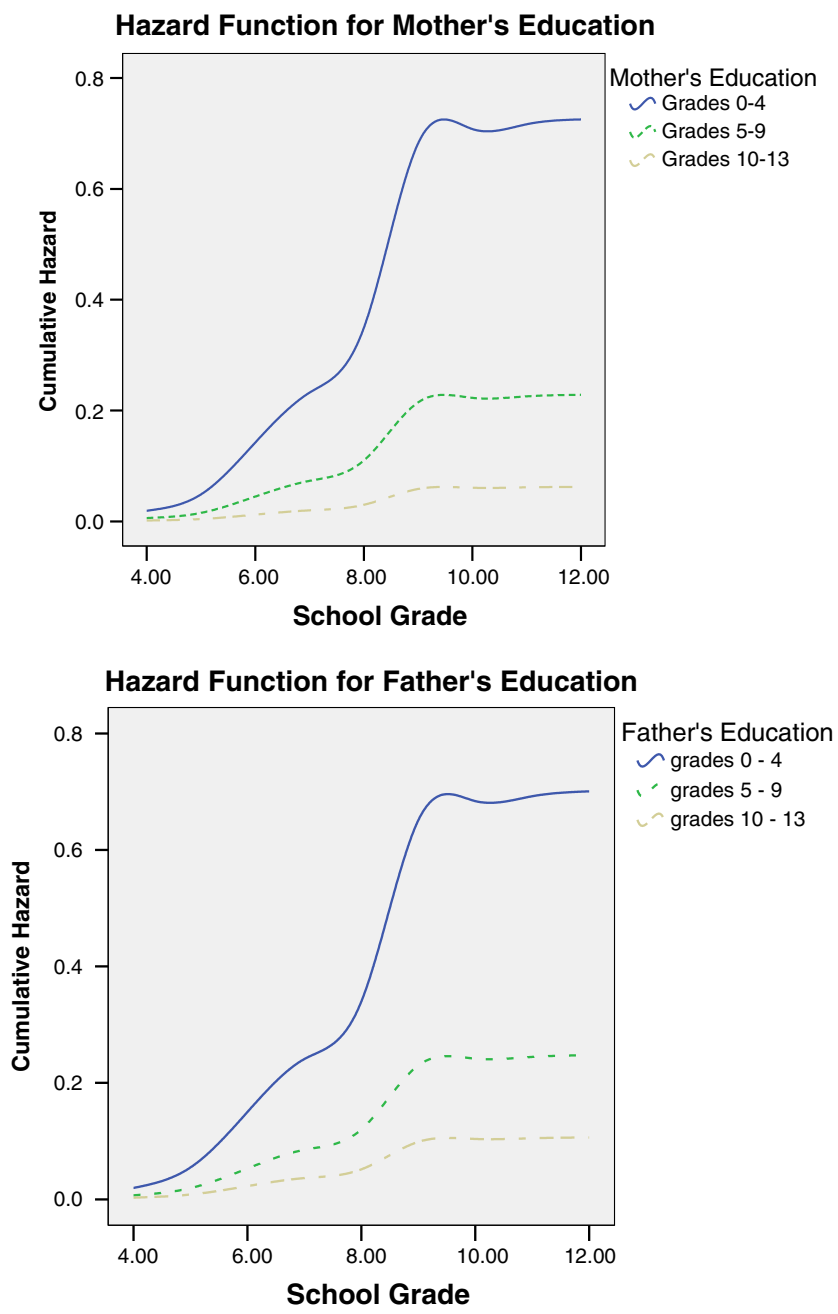

Fig. 2. Hazard functions of low, medium, and high mother's and father's education. 


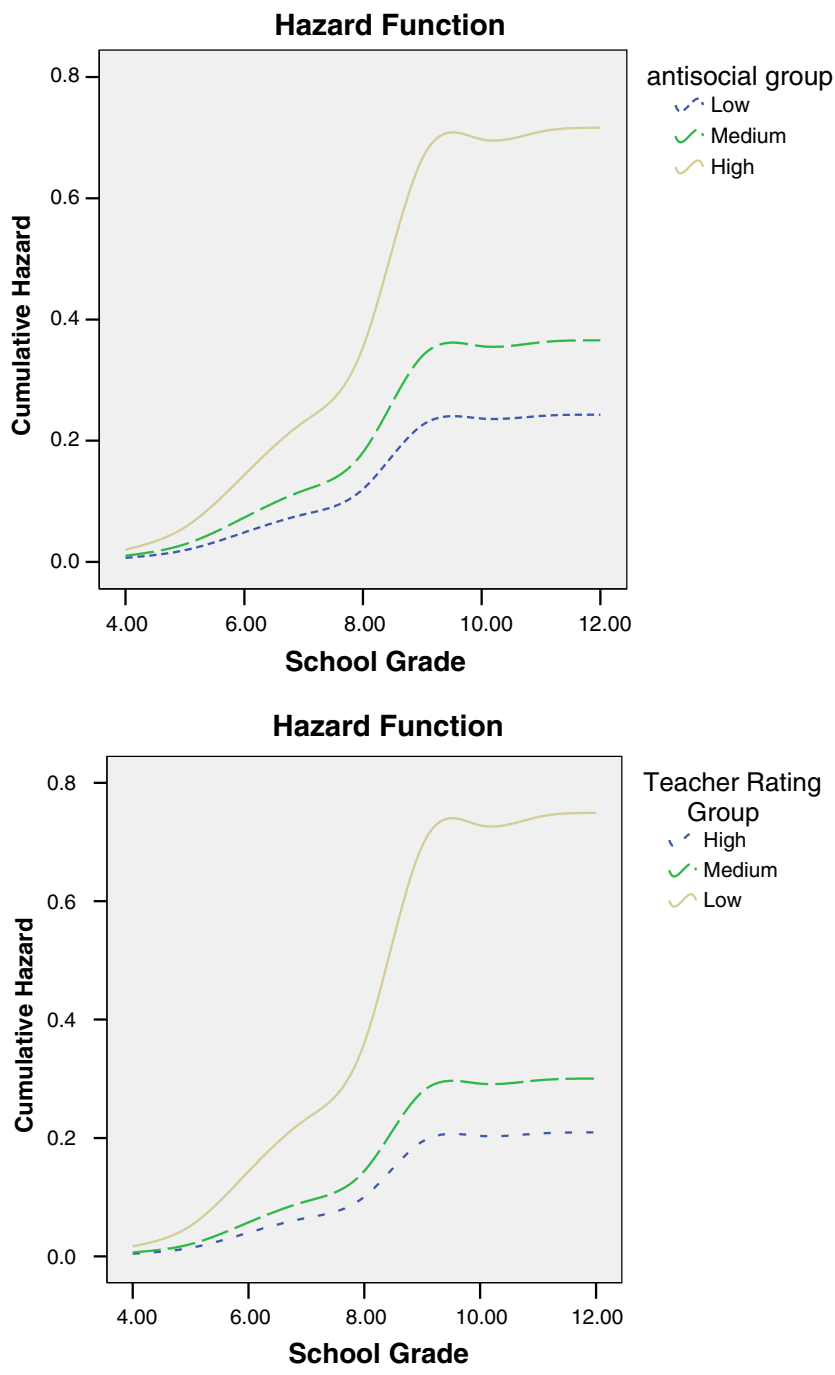

Fig. 3. Hazard functions for low, medium, and high antisocial behavior and teacher ratings.

It can be seen from Fig. 3 that as children become more antisocial, the probability of school dropout increases accordingly and significantly. The higher the antisocial behavior, the greater the probability of school dropout. Moreover the increases in the probability of school dropout are evident across the course of time. A similar effect was observed for the teacher's ratings of child behavior which is also displayed in Fig. 3. As the teacher's rating of behavior becomes more severe, the probability of school dropout increases concomitantly.

Among the single predictor models, only the urban-rural school context variable had no discernable effect on predicting the probability of school dropout. This was confirmed both in the individual models and in the $\chi^{2}$ difference tests between Step 4 and Step 5 of the hierarchical model - the urban-rural school variable added nothing unique to the prediction model that was not already absorbed by other variables. 
The hierarchical proportional hazard regression models revealed a similar picture to the single predictor model even while controlling for any multicollinearity that may exist among the predictors. A few observations about the hierarchical models presented in Table 3 are illustrative. The sample size of the hierarchical model is smaller than for the individual models because the software (e.g., SPSS, SAS) requires listwise deletion of incomplete data. A total of 88 dropout and 204 censored observations had complete data such that the hierarchical models are based on a sample size of 292 students.

Examination of Table 3 reveals that at Step 2 of the model, the increment to predictability of the hazard is significantly augmented by the set of both mother's and father's education $\left(\chi^{2}=66.00, p<.001\right)$, while the unique contribution of mother's education is statistically significant $\left(\chi^{2}=19.05, p<.001\right)$, and the unique contribution of father's education is not statistically significant $\left(\chi^{2}=.96, p=.326\right)$. We know from the single model tests that each of these variables is a significant predictor of the criterion, but in the multiple predictor model father's education is redundant with mother's education, adds little to the prediction over and above mother's education, and is therefore non-significant. Thus, it is not that father's education is unimportant; it is simply redundant with mother's education. It is probably best to think of the contribution of parents' education as reflected in the increment at Step 2. Almost identical comments could be made about mother's and father's SES at Step 4 in which mother's SES is a little stronger than father's SES. Nonetheless, the set of mother's and father's SES does not make an incrementally significant contribution to the model, allowing for the remaining variables in the model at Step 4 $\left(\chi^{2}=4.33, p=.115\right)$. Mother's and father's SES and education are highly related, and probably constitute a single "family status" factor rather than individually unique predictor variables.

At Step 3 of the hierarchical analysis, the behavioral variables including student ratings of antisocial behaviors, parent's ratings on the CBCL, and teacher's ratings of the child's behavior at the first testing period in 1993 are a significantly unique set of predictors of the probability of school dropout over the school grades $2-12\left(\chi^{2}=33.84, p=<.001\right)$. The partialled coefficients of the model, however, suggest that the student and teacher ratings are significant contributors to the prediction of dropout status, while the parents' ratings are not. Since the parents' ratings were statistically significant in the single predictor model, it appears that they are largely redundant with the remaining variables and add no unique element of prediction. While the odds ratio for the parents' CBCL ratings is 1.00 (implying no relationship), the odds ratio of antisocial behaviors, for example, is 1.05 , meaning that the odds are about $1.05-1$ for a one unit change in the rating scale. The absolute value of the odds ratio for antisocial behaviors (range $=0-34$ ) and teacher's ratings (range $=0-147$ ) appears rather small only because of the nature of the underlying scale. Scales with large ranges typically have smaller absolute odds ratios on a per-unit basis. By contrast, scales such as SES (range $=1-5$ ) with shorter ranges, tend to show higher odds ratios per unit change; the odds ratio of 1.49 for mother's SES, for example, suggests that a one unit shift in SES implies a $50 \%$ increase in the probability of dropout status.

Finally, at Step 5 of the hierarchical analysis it is seen that the school variable of urbanrural adds little or nothing to the prediction of the probability of school dropout, over and above the other predictor variables that are already in the model. It was also observed that as a single predictor, the urban-rural school distinction was not related to differential rates of school dropout. 


\section{Discussion}

The results found in this study are consistent with a developmental and systemic approach to psychological development. The first result we would like to stress is the fact that a significant number of students dropout of school at the 9th grade, which is the last year of compulsory education in Portugal and the last period of time that sociological "pressure" acts as a marker. Second, we are impressed by the fact that the majority of school dropouts are males; the probability of dropping out is significantly higher for males than females at each grade level. This finding suggests that there may be a complex process at work in the construction of social expectations, based on gender.

One of the most striking results that emerged in this study was the finding that the presence of early antisocial behaviors was highly predictive of school dropout. The presence of signs indicating behavioral problems, especially as rated by teachers, was also found to be an important indicator that should be taken into account in the prediction of school dropout. We would expect that these variables, given their contextual and iatrogenic value in the personal development process, should exert an important influence on the overall socialization process. In addition to the above, the most intriguing finding that emerged from this study was the identification of the protective/resilience factors related to "family status." Parental influences, such as mother's and father's education, and mother's and father's socioeconomic status, appear to be important predictor variables with respect to the stability of the developmental processes that are related to school dropout.

What we have found in this research represents a confirmation of Vondracek et al.'s (1986) model, which asserts that the developing person forms an identity in an interactive and exponential way, wherein individual characteristics interact in successive feedback loops with the context, resulting eventually in their unique personal behavioral patterns. Further research is needed, however, searching for not only general patterns, pathways, and directions over time, but for several specific trajectories that are possible within this developmental process. Different trajectories could be imagined whereby we construct scenarios consisting of possible different initial conditions of development, chaotic and unpredictable events in life, and individual and social auto-organizational capabilities of the system and of its actors.

In brief, the premature transition from school to work appears to be the result of a complex process that occurs over a long period of time. Moreover, it begins very early in life as demonstrated by the finding that the transition can be predicted from the earliest years of schooling. For example, we observed that adolescents who dropout of school could be reliably differentiated from the adolescents who remain in school along several different dimensions, including family education and economic variables and antisocial behaviors that are observed as early as the second grade. Many of the difficulties of the adolescents who dropped out of school are already visible in elementary school years. Certainly, these early prediction variables will have a cumulative effect along the paths that individuals will travel through their behavioral, social, and career trajectories. The results presented here clearly emphasize the role of the many different social, personal, and familial contexts and influences that bear upon an individual's developmental progress - each of these contexts and influences have implications for counseling.

Our results suggest that intervention programs in this area should take into consideration a great variety of factors, take place very early in the school years, involve professionals from different specialty areas, and take into account the real possibility of 
different typologies for school dropouts. As Herr and Cramer (1996) recommended, school counselors should act in three C's: counseling, coordinating, and consulting. Given the personal, relational, and organizational dimensions of this problem, solutions should be designed from an integrated perspective, and career education and guidance methodologies should be implemented from this integrated perspective.

Because of its strong rationale and structure, models like the DCM of Vondracek could provide a solid framework for establishing the basis of intervention. The multiple interrelations between the different ecosystems that are central to this model should act in practice as internal linkages within a complex educational and social macro-system, wherein social, educational, and family policies should be re-directed. The integration of educational activities, training strategies, and work experiences could be an alternative to the prevailing model, which often portrays school as the exclusive (and preferred) scenario, to the detriment of those who seek other ways of transitioning into adulthood. The reasons expressed by the participants to explain dropout, and concomitantly their career expectations, represent a rich resource for building new approaches to career guidance. The processing of this information should feed back to the school system. As Herr and Cramer claim - "career guidance in the elementary school is not intended to force children to make premature choices but to avoid premature closure of future options" (op. cit., p. 349). Following Herr and Cramer, we would like to add that career development is more than just vocational development, but should be thought of as development in context. This is particularly true when considering the processes that underlie educational, learning, and occupational socialization. Thus, as clearly evidenced in the pattern of our results, counseling interventions must address personal, parental, school, and social dimensions and must do so beginning in the early years of childhood.

With respect to further empirical research, we would suggest that the next steps should include constructing and testing theoretical models that capture the richness of the multivariate relations that exist between variables. Personality and social dimensions must be infused into developmental studies, like pieces of a hologram. The limitations in our current understanding of early career development derive from the prevailing fragmented view of development and transitional processes, and they will not disappear on their own (Bloch, 2005). We could think that, perhaps, the personality "weaknesses" of individuals only are expressed in "non-strong environments." Such "weaknesses" (often manifested through problem behaviors) should not be considered as if they occurred in a vacuum, but should be thought of as being integral to the social and environmental contexts in which kids live; that is a hypothesis that should be studied, particularly in the area of vocational and career dimensions of human and behavioral development.

\section{References}

Achenbach, T. M. (1991a). Manual for the child behavior checklist/4-18 and 1991 profile. Burlington, VT: University of Vermont, Department of Psychiatry.

Achenbach, T. M. (1991b). Manual for the teacher report form and 1991 profile. Burlington, VT: University of Vermont, Department of Psychiatry.

Bandura, A. (1986). The social foundations of thought and action: A social cognitive theory. Englewood Cliffs, NJ: Prentice-Hall.

Bloch, D. P. (2005). Complexity, chaos, and nonlinear dynamics: A new perspective on career development theory. The Career Development Quarterly, 53, 194-207.

Collin, A., \& Young, R. A. (Eds.). (2000). The future of career. Cambridge: Cambridge University Press. 
Cox, D. R. (1972). Regression models and life tables (with discussion). Journal of the Royal Statistics Society, Series B, 34, 187-220.

Cox, D. R., \& Oakes, D. (1984). Analysis of survival data. London: Chapman and Hall.

Crites, J. O. (1969). Vocational psychology: The study of vocational behavior and development. New York: McGraw-Hill.

Fonseca, A. C., Rebelo, J. A., \& Damião, M. H. (2005). The development of juvenile delinquency: Are children with hyperactivity and early antisocial behaviour at a higher risk? In R. A. Gonçalves, R. Roesch, C. Machado, C. Soeiro, \& F. Winkel (Eds.), Assessment, intervention and legal issues with offenders and victims (pp. 119-126). Bruxelas: Politea.

Fonseca, A. C., Simões, A., Rebelo, J. A., \& Ferreira, J. A. (1995). Hyperactivity and conduct disorder among Portuguese children and adolescents: Data from parents'and teacher'reports. In J. Sergeant (Ed.), Eunethydis: European approaches to hyperkinetic disorder. Zurich: Egg.

Ford, D. H., \& Lerner, R. M. (1992). Developmental systems theory: An integrative approach. London: Sage Publications.

Gottfredson, L. S. (1996). Gottfredson's theory of circumscription and compromise. In D. Brown \& L. Brooks (Eds.), Career choice and development (3rd ed., pp. 179-232). San Francisco, CA: Jossey-Bass.

Hartung, P. J., Porfeli, E. J., \& Vondracek, F. W. (2005). Child vocational development: A review and reconsideration. Journal of Vocational Behavior, 66, 385-419.

Herr, E. L., \& Cramer, S. H. (1996). Career guidance and counseling through the life span: Systematic approaches. New York, NY: Longman.

Lee, E. T. (1992). Statistical methods for survival data analysis. New York: John Wiley.

Lent, R. W., Brown, S. D., \& Hackett, G. (1996). Career development from a social cognitive perspective. In D. Brown \& L. Brooks (Eds.), Career choice and development (3rd ed., pp. 373-421). San Francisco, CA: JosseyBass.

Loeber, R., Stouthamer-Loeber, M., Van Kamen, W. B., \& Farrington, D. P. (1989). Development of a new measure of self-reported and anti-social behavior for young children: Prevalence and reliability. In M. W. Klein (Ed.), Cross national research and self-reported crime and delinquency (pp. 203-225). Dordrech: KluwerNijhoff.

Marcia, J. E. (1976). Studies in ego identity. Burnaby, BC: Simon Fraser University.

Miller, R. G. (1981). Survival analysis. New York: John Wiley.

Patton, W., \& McMahon, M. (1998). Career development and systems theory: A new relationship. New York: Wadsworth.

Pepper, S. C. (1942). World hypotheses: A study in evidence. Berkeley, CA: University of California Press.

Reitzle, M., \& Vondracek, F. W. (2000). Methodological avenues for the study of career pathways. Journal of Vocational Behavior, 57, 445-467.

Reitzle, M., Vondracek, F. W., \& Silbereisen, R. K. (1998). Timing of school-to-work transitions: A developmental-contextual perspective. International Journal of Behavioral Development, 22, 7-28.

Savickas, M. L. (2002). Career construction: A developmental theory of vocational behavior. In D. Brown and Associates, Career Choice and Development (4th ed., pp. 149-205). San Francisco, CA: Jossey Bass.

Savickas, M. L. (2003a). Career counseling in the next decade. Career Development Quarterly, 52, 4-7.

Savickas, M. L. (2003b). Advancing the career counseling profession: Objectives and strategies for the next decade. Career Development Quarterly, 52, 87-96.

Savickas, M. L. (2005). The theory and practice of career construction. In R. W. Lent \& S. D. Brown (Eds.), Career development and counseling: Putting theory and research to work (pp. 42-70). New York: Wiley.

Selvin, S. (1991). Statistical analysis of epidemiologic data. New York: Oxford University Press.

Simões, A., Ferreira, J. A., Fonseca, A. C., \& Rebelo, J. A. (1995). Um estudo dos distúrbios do comportamento e dificuldades de aprendizagem no ensino básico: opções metodológicas. Revista Portuguesa de Pedagogia, $X X I X, 3,55-68$.

Singer, J. D., \& Willett, J. B. (1991). Modeling the days of our lives: Using survival analysis when designing and analyzing longitudinal studies of duration and the timing of events. Psychological Bulletin, 110, 268-290.

Super, D. E. (1957). The psychology of careers. New York: Harper.

Super, D. E. (1963). Self-concepts in vocational development. In D. E. Super, R. Starishevsky, N. Matlin, \& J. P. Jordaan (Eds.), Career development: Self-concept theory (pp. 1-16). New York: College Entrance Examination Board.

Super, D. E. (1980). A life-span, life-space approach to career development. Journal of Vocational Behavior, 16, 282-298. 
Super, D. E. (1981). A developmental theory: Implementing a self-concept. In D. H. Montross \& C. J. Shinkman (Eds.), Career development in the 1980's. Springfield, IL: Charles C. Thomas.

Super, D. E. (1990). Career choice and development. San Francisco, CA: Jossey-Bass.

Super, D. E., Savickas, M. L., \& Super, C. M. (1996). The life-span, life-space approach to careers. In D. Brown \& L. Brooks (Eds.), Career choice and development (3rd ed., pp. 121-178). San Francisco, CA: Jossey-Bass.

Vondracek, F. W. (2001). The childhood antecedents of adult careers: Theoretical and empirical considerations. In R. K. Silbereisen \& M. Reitzle (Eds.), Bericht über den 42. Kongreß der Deutschen Gesellschaft fur Psychologie in Jena 2000 (pp. 265-276). Lengerich, Germany: Pabst Science Publishers.

Vondracek, F. W., Lerner, R. M., \& Schulenberg, J. E. (1986). Career development: A life-span developmental approach. Hillsdale, NJ: Erlbaum.

Vondracek, F. W., \& Porfeli, E. J. (2002). Integrating person- and function-centered approaches in career development theory and research. Journal of Vocational Behavior, 6, 386-397.

Vondracek, F. W., \& Porfeli, E. J. (2004). Perspectives historiques et contemporaines sur la transition de l'école au travail: Apports théoriques et méthodoliques du modéle développemental-contextuel (Historical and contemporary views on the transition from school to work: Theoretical and methodological advances from a developmental-contextual perspective.). L'Orientation Scolaire et Professionnelle, 33(3), 351-374.

Vondracek, F. W., Reitzle, M., \& Silbereisen, R. (1999). The influence of changing contexts and historical time on the timing of initial vocational choices. In R. K. Silbereisen \& A. von Eye (Eds.), Growing up in times of social change (pp. 151-169). New York: DeGruyter.

Wiesner, M., Vondracek, F. W., Capaldi, D. M., \& Porfeli, E. J. (2003). Childhood and adolescent predictors of early adult career pathways. Journal of Vocational Behavior, 63, 305-328.

Young, R. A., Valach, L., \& Collin, A. (1996). A contextual explanation of career. In D. Brown \& L. Brooks (Eds.), Career choice and development (3rd ed., pp. 477-512). San Francisco, CA: Jossey-Bass. 